\title{
Incorporation of Dental Health Screening in Paediatric Office Practice
}

\author{
Dagli PP1, Singh J ${ }^{2}$, Sheth J ${ }^{3}$, Kakkad K ${ }^{4}$
}

\begin{abstract}
Introduction: Dental health problems in children are often overlooked. Poor oral health negatively affects growth, learning, communication, self-esteem and rarely can also lead to serious fatal infection. Paediatrician can play key role in screening dental health problems. The objectives of this study were to screen children for dental caries in paediatric office and correlate with socio-demographic, dietary and oral hygiene risk factors. Material and Methods: After basic oral health training, paediatrician assessed oral health risk factors with pre-validated questionnaire and carried out dental examination at paediatric OPD. Results: Dental health problems were found in $364(42.8 \%)$ out of 850 subjects. Age was significantly associated $(p<0.0001)$ with type of teeth involved. Incisors were most affected in infants and involvement of posterior teeth increased with age. Statistically significant $(p<0.05)$ oral health risk factors were increasing age, lower socio-economic status, malnutrition, lower parents' education, positive family history, bottle feeding, increased consumption of biscuits, fizzy drinks and chewing gum; delayed start and less time spent on brushing, infrequent change of toothbrush, incorrect brushing technique, inadequate parental knowledge and supervision. Conclusion: Dental screening can easily be incorporated in busy paediatric practice. An identification and record of individual risk factor is useful in selecting counselling strategies and monitoring.
\end{abstract}

Key words: Oral health, Oral health risk factors, Dental caries

\section{Introduction}

$\mathrm{D}$ ental health problems are one of the major and often overlooked public health problems in India as well as across the globe. WHO recognizes the oral health as an integral part of general health ${ }^{1}$. According to National Oral Health Survey, India is facing a silent epidemic of dental caries. It is the most common chronic childhood disease affecting more than $80 \%$ children under 15 years of age and only $2 \%$ population visit dentist ${ }^{2}$. Poor oral health negatively affects growth, nutrition, learning, communication, appearance, quality of life, self-esteem and rarely can also lead to serious fatal infection ${ }^{2,3,4,5}$. A dentist is consulted less often due to lack of awareness, prolonged asymptomatic course of the disease and unmet dental health needs.
${ }^{1}$ Dr. Pallavi Parag Dagli, MBBS, D. Paed, MD, Associate Professor, Department of Paediatrics, Sheth VS General Hospital, ${ }^{2} \mathrm{Dr}$. Jyotsna Singh, MBBS, MD, Ex-Resident Paediatrics, ${ }^{3} \mathrm{Dr}$. Jay Sheth, MBBS, MD, Associate Professor, Department of Community Medicine, ${ }^{4} \mathrm{Dr}$. Khyati Kakkad, MBBS. MD, Associate Professor, Department of Paediatrics. All from Smt NHL Municipal Medical College, Ahmedabad, India.

\section{Address for correspondence \\ Dr. Pallavi Parag Dagli \\ 7, Shrushti bungalows-part 1 , \\ Shyamal cross roads, Satellite, \\ Ahmedabad- 380015, Gujarat, India. \\ Tel No; +919925049194 \\ E-mail: paragpallavi2000@gmail.com}

\section{Acknowledgements: None \\ Funding: Nil \\ Conflict of Interest: None \\ Permission from IRB: Yes}

\section{How to cite}

Dagli PP, Singh J, Sheth J, Kakkad K. Incorporation of Dental Health Screening in Paediatric Office Practice. J Nepal Paediatr Soc 2017;37(2):138-146.

doi: http://dx.doi.org/10.3126/jnps.v37i2.17028

This work is licensed under a Creative Commons Attribution 3.0 License. 
Many international guidelines recommend, a paediatrician being the first health care provider has an important role in risk assessment and screening children for dental caries as she/he often is in contact with children from birth to adolescence ${ }^{4.6 .7}$. The periodicity of well-child visits provide numerous opportunities to the paediatricians to assess risk of caries and to educate their families regarding the importance of oral health and to begin the process of primary prevention of early childhood caries, $4,6,7,8,9$. Risk assessment is a key element of comprehensive care with the goal to prevent the disease by early identification and minimizing causative factors (e.g. dietary habits, plaque accumulation) and optimizing protective factors (e.g. oral hygiene, fluoride exposure $)^{5,10,11,12}$. Paediatricians overwhelmingly believe that they have an important role in the promotion of oral health but main constraints are time factor and lack of familiarity with oral health issues ${ }^{4}$, 13,14. Traditionally, paediatricians have been examining child's throat, tonsils and pharynx. To incorporate oral health in office practice one must examine gum and teeth $^{4}$. It is important for a paediatrician to be able to recognize normality and deviations rather than to be able to identify specific pathology ${ }^{4}$.

The objectives of our study were to screen children for dental health problems in paediatric office practice and to correlate socio-demographic, dietary and oral hygiene risk factors with dental health problems.

\section{Material and Methods}

Before commencing study, extensive literature on dental caries and risk factors was reviewed. Available risk assessment tools from different guidelines (WHO, AAP, AAPD) meta-analysis, oral health surveys and National oral health program were reviewed to determine the socio-demographic, dietary and oral hygiene risk factors recommended for assessment by non-dental care providers ${ }^{1,2,12,12,16,17}$. Resulting questionnaire was validated and reliability coefficient was 0.83 . The examiners (one associate professor of paediatrics and a paediatric resident) received two days of training in oral health assessment from a dentist. The training consisted review of clinical photographs of the normal dentition, slide presentations of various dental health problems, posters and videos illustrating dental caries in various stages of progression, tooth-brushing technique and counselling. A pilot study was carried out on dental screening by both a dentist and a paediatrician to calibrate and validate the examination. We obtained written informed consent from the guardians of all study subjects.

This study was carried out from January to October 2013, in a tertiary care teaching hospital at Ahmedabad,
Gujarat, catering mainly low income group patients. This is a cross-sectional observational study involving 850 patients up to 15 years; attending paediatric OPD for minor ailments for whom complete data (questionnaire and oral cavity examination) was available. The patients with malocclusion; malformation and surgery involving oral cavity were excluded.

Parents' response to questionnaire was recorded in waiting area of paediatric OPD. Dietary habits included breastfeeding and bottle feeding ( $\geq 3$ months duration) in children up to 3 years of age, night time bottle feeding, consumption of biscuits per day by 24 hour recall method and consumption of fizzy drinks, fruit drinks, sweets/chocolates, chewing gum and tobacco per week by seven day recall method.

Oral hygiene practices of a child regarding age of start, frequency, timings, technique, duration and parental supervision of brushing the teeth were recorded. The knowledge and brushing technique of the parents was assessed using denture model. Frequency and criteria of changing toothbrush were recorded. Type and amount of preparation to clean the teeth e.g. paste or powder was recorded. The amount was ascertained according to the size of paste / length of the bristles covered. The nutrition status was assessed as per the IAP classification up to five years of age and using BMI beyond five years age. Modified Prasad Classification version 2012 was used to determine socio-economical class of the subjects.

Oral cavity examination was conducted by single paediatrician (to avoid inter-examiner variability) in wellilluminated paediatric OPD using torch and spatula without any dental probe or mirror. A meticulous surfaceby-surface examination of teeth and gum was carried out after oral rinse and drying if required. Dental health problems were recorded as precarious lesions like plaque and white opaque spots according to the type of tooth and the arch involved. After evaluation, parents were counselled for proper dietary oral hygiene practices ${ }^{4,11,12}$. Appropriate dental reference was advised.

Data were analysed using IBM SPSS version 20 and appropriate statistical tools.

\section{Results}

We carried out dental health assessment of 850 subjects. The socio-demographic characteristics of study subjects are presented in Table 1.

The source of drinking water for all the study participants was same (From municipal water supply). This was inquired for background fluoride information. Past history of dental check-up was found in only 11 
$(1.3 \%)$ children and only $6(0.7 \%)$ had gotten some dental intervention in the form of filling. Breast-feeding had been given to all children up to two years of age. Out of 340 children of three year age, 33 (9.67\%) were given bottle-feeding and all 33 received night bottlefeeding. Tobacco consumption was not found in any subject. Other details of dietary habits and nutritional assessment of subjects are shown in Table 3.

Out of 850 children, 500 (58.8\%) had started brushing teeth, their oral hygiene practices are presented in Table 2.

Mean age of starting to toothbrush was three years. All subjects used paste in adequate amount. Fluoride content of toothpaste could not be inquired for all. No particular criterion for changing the brush (for example fraying of bristles, duration of usage etc.) was found.

Dental health problems were found in 364 (42.8\%) out of total 850 subjects. $356(94.8 \%)$ subjects were asymptomatic for dental complaints. Dental problems were found in all age groups. As the age increases, the incidence of dental caries increases. Age was found to be significantly $(p<0.0001)$ associated with dental problems.

Plaque was the commonest dental health problem affecting $225(26.4 \%)$ subjects followed by caries affecting $175(20.5 \%)$ subject with a total of 234 carious teeth. 84 subjects had both plaque and caries. White opaque spots were found in $33(9 \%)$ subjects.

As Table 3 shows, molars were the most commonly affected teeth having a predilection for mandibular arch. Canines were affected the least. Age-wise teeth involvement $(n=234)$ is shown in Figure 1.

Incisors were the most affected in infants and toddlers and involvement of the posterior teeth increased with age. Significant association ( $p$-value $<0.0001$ ) was found between age of the subjects and the type of teeth involved. All the 15 patients of cerebral palsy had dental caries.

Table 4 represents dental health problems and correlation with the different variables.

Table 1: Socio-demographic background of study subjects $(n=850)$

\begin{tabular}{|c|c|c|}
\hline Variables & Number & Percentage (\%) \\
\hline \multicolumn{3}{|l|}{ Age groups (years) } \\
\hline $0-3$ & 340 & 40 \\
\hline $4-6$ & 233 & 27.4 \\
\hline $7-10$ & 200 & 23.5 \\
\hline $11-15$ & 77 & 9.1 \\
\hline \multicolumn{3}{|l|}{ Gender } \\
\hline Male & 463 & 54.5 \\
\hline Female & 387 & 45.5 \\
\hline \multicolumn{3}{|c|}{ Socio-Economic class (MPC 2012) } \\
\hline 1 & 0 & 0 \\
\hline II & 12 & 1.4 \\
\hline III & 76 & 8.9 \\
\hline IV & 762 & 89.6 \\
\hline V & 0 & 0 \\
\hline \multicolumn{3}{|l|}{ Father's education } \\
\hline Illiterate & 86 & 10.1 \\
\hline Just literate & 210 & 24.7 \\
\hline Primary & 316 & 37.2 \\
\hline Secondary & 146 & 17.2 \\
\hline Senior secondary & 68 & 8 \\
\hline Graduate & 24 & 2.8 \\
\hline \multicolumn{3}{|l|}{ Mother's education } \\
\hline Illiterate & 226 & 26.6 \\
\hline Just literate & 214 & 25.2 \\
\hline Primary & 277 & 32.5 \\
\hline Secondary & 78 & 9.2 \\
\hline Senior secondary & 44 & 5.1 \\
\hline Graduate & 11 & 1.3 \\
\hline
\end{tabular}


Table 2: Oral health behaviour and hygiene practices of subjects practicing tooth brushing $(n=500)$

\begin{tabular}{|c|c|c|}
\hline Age of start of brush (years) & Number & Percentage (\%) \\
\hline $2-2.9$ & 19 & 3.8 \\
\hline $3-3.9$ & 238 & 47.6 \\
\hline $4-4.9$ & 222 & 44.4 \\
\hline 5 and above & 21 & 4.2 \\
\hline \multicolumn{3}{|l|}{ Frequency Of Tooth brushing } \\
\hline Once per day & 487 & 97.4 \\
\hline Less than once & 23 & 4.6 \\
\hline \multicolumn{3}{|l|}{ Time of tooth brushing } \\
\hline Morning & 500 & 100 \\
\hline Night & 0 & 0 \\
\hline Other & 0 & 0 \\
\hline \multicolumn{3}{|l|}{ Brushing Habit } \\
\hline Brushing after snacks/sugary food & 0 & 0 \\
\hline \multicolumn{3}{|l|}{ Time spent on brushing (Seconds) } \\
\hline $30-44$ & 183 & 36.6 \\
\hline $45-59$ & 136 & 27.2 \\
\hline $60-120$ & 181 & 36.2 \\
\hline$\geq 120$ & 0 & 0 \\
\hline \multicolumn{3}{|l|}{ Item used for tooth brushing } \\
\hline Brush + Toothpaste & 493 & 98.6 \\
\hline Tooth powder & 6 & 1.2 \\
\hline Datun (Neem) & 1 & 0.2 \\
\hline \multicolumn{3}{|c|}{ Time of brush change after usage (In months) } \\
\hline 2 & 13 & 2.6 \\
\hline 3 & 376 & 75.2 \\
\hline 4 & 98 & 19.6 \\
\hline 5 & 5 & 1 \\
\hline 6 & 8 & 1.6 \\
\hline \multicolumn{3}{|l|}{ Technique of brushing } \\
\hline Correct & 28 & 5.6 \\
\hline Incorrect & 472 & 94.4 \\
\hline \multicolumn{3}{|l|}{ Parental Supervision } \\
\hline Absent & 453 & 90.6 \\
\hline Present & 47 & 9.4 \\
\hline
\end{tabular}

Table 3: Dental caries and specific tooth involvement $(n=234)$

\begin{tabular}{cccc}
\hline Type of teeth & Number & Type of teeth & Number \\
\hline Upper incisors & $37(15.8 \%)$ & Lower incisors & $3(1.3 \%)$ \\
\hline Upper canines & $16(6.8 \%)$ & Lower canines & $5(2.1 \%)$ \\
\hline Upper premolars & $24(10.2 \%)$ & Lower premolars & $21(8.9 \%)$ \\
\hline Upper molars & $50(21.3 \%)$ & Lower molars & $78(33.3 \%)$ \\
\hline
\end{tabular}


Table 4: Dental health problems and correlation with the different variables

\begin{tabular}{|c|c|c|c|c|}
\hline Variable & $\begin{array}{l}\text { No of subjects } \\
\qquad(n=850)\end{array}$ & $\begin{array}{l}\text { Subjects without } \\
\text { dental problems } \\
\qquad(n=486)\end{array}$ & $\begin{array}{c}\text { Subjects with } \\
\text { dental problems } \\
(n=364)\end{array}$ & $p$-value \\
\hline \multicolumn{5}{|c|}{ Age groups (years) } \\
\hline $0-3$ & 340 & 239 & 101 & \multirow{4}{*}{$p<0.001$} \\
\hline $4-6$ & 233 & 129 & 104 & \\
\hline $7-10$ & 200 & 99 & 101 & \\
\hline $11-15$ & 77 & 19 & 58 & \\
\hline \multicolumn{5}{|c|}{ Socio-Economic class (MPC 2013) } \\
\hline 1 & 0 & 0 & 0 & \multirow{5}{*}{$p=0.02$} \\
\hline II & 12 & 11 & 1 & \\
\hline III & 76 & 54 & 22 & \\
\hline IV & 762 & 421 & 341 & \\
\hline V & 0 & 0 & 0 & \\
\hline \multicolumn{5}{|l|}{ Father's education } \\
\hline Illiterate & 86 & 39 & 47 & \multirow{6}{*}{$p=0.04$} \\
\hline Just literate & 210 & 125 & 85 & \\
\hline Primary & 316 & 176 & 140 & \\
\hline Secondary & 146 & 85 & 61 & \\
\hline Senior secondary & 68 & 39 & 29 & \\
\hline Graduate & 24 & 22 & 2 & \\
\hline \multicolumn{5}{|c|}{ Mother's education } \\
\hline Illiterate & 226 & 110 & 116 & \multirow{6}{*}{$p=0.02$} \\
\hline Just literate & 214 & 125 & 89 & \\
\hline Primary & 277 & 163 & 114 & \\
\hline Secondary & 78 & 44 & 34 & \\
\hline Senior secondary & 44 & 34 & 10 & \\
\hline Graduate & 11 & 10 & 1 & \\
\hline \multicolumn{5}{|c|}{ Parental Knowledge of brushing technique } \\
\hline Correct & 45 & 37 & 8 & \multirow{2}{*}{$p<0.0001$} \\
\hline Incorrect & 805 & 449 & 356 & \\
\hline \multicolumn{5}{|c|}{ Family History of Dental caries } \\
\hline Negative & 626 & 401 & 225 & \multirow{2}{*}{$p<0.001$} \\
\hline Positive & 224 & 85 & 139 & \\
\hline \multicolumn{5}{|l|}{ Nutritional status } \\
\hline \multicolumn{5}{|c|}{ PEM Grade ( $<5$ years) } \\
\hline I & 41 & 37 & 4 & \multirow{5}{*}{$p<0.0001$} \\
\hline II & 202 & 166 & 36 & \\
\hline III & 247 & 131 & 116 & \\
\hline IV & 20 & 1 & 19 & \\
\hline V & 0 & 0 & 0 & \\
\hline \multicolumn{5}{|l|}{ BMI (> 5 years) } \\
\hline Underweight & 292 & 130 & 162 & \multirow{4}{*}{$p=0.8$} \\
\hline Normal & 48 & 20 & 28 & \\
\hline Overweight & 0 & 0 & 0 & \\
\hline Obese & 0 & 0 & 0 & \\
\hline \multicolumn{5}{|c|}{ Bottle feeding $(n=340)$} \\
\hline Absent & 307 & 230 & 77 & \multirow{2}{*}{$p<0.0001$} \\
\hline Present & 33 & 9 & 24 & \\
\hline \multicolumn{5}{|c|}{ Frequency of eating biscuits per day } \\
\hline 0 & 14 & 10 & 4 & \\
\hline 1 & 72 & 67 & 5 & \\
\hline 2 & 353 & 210 & 143 & $p<0.0001$ \\
\hline 3 & 388 & 188 & 200 & \\
\hline$\geq 4$ & 23 & 11 & 12 & \\
\hline
\end{tabular}


Table 4 cont ...

\section{Frequency of Fizzy drink per week}

\begin{tabular}{|c|c|c|c|c|}
\hline 0 & 559 & 365 & 194 & \multirow{5}{*}{$p<0.0001$} \\
\hline 1 & 8 & 7 & 1 & \\
\hline 2 & 96 & 44 & 52 & \\
\hline 3 & 164 & 62 & 102 & \\
\hline$\geq 4$ & 23 & 8 & 15 & \\
\hline \multicolumn{5}{|c|}{ Frequency of Chocolate/sweets per week } \\
\hline 0 & 599 & 357 & 242 & \multirow{6}{*}{$p=0.06$} \\
\hline 1 & 50 & 27 & 23 & \\
\hline 2 & 96 & 54 & 42 & \\
\hline 3 & 87 & 42 & 45 & \\
\hline 4 & 17 & 6 & 11 & \\
\hline$\geq 5$ & 1 & 0 & 1 & \\
\hline \multicolumn{5}{|c|}{ Frequency of Chewing gum per week } \\
\hline 0 & 809 & 470 & 339 & \multirow{5}{*}{$p<0.01$} \\
\hline 1 & 2 & 1 & 1 & \\
\hline 2 & 11 & 4 & 7 & \\
\hline 3 & 27 & 10 & 17 & \\
\hline$\geq 4$ & 1 & 1 & 0 & \\
\hline \multicolumn{5}{|c|}{ Frequency of Fruit drink per week } \\
\hline 0 & 551 & 337 & 214 & \multirow{5}{*}{$p<0.01$} \\
\hline 1 & 12 & 8 & 4 & \\
\hline 2 & 94 & 51 & 43 & \\
\hline 3 & 171 & 79 & 92 & \\
\hline$\geq 4$ & 22 & 11 & 11 & \\
\hline \multicolumn{5}{|c|}{ Tooth brushing habits $(n=500)$} \\
\hline \multicolumn{5}{|c|}{ Age of starting brushing teeth (years) } \\
\hline $2-2.9$ & 19 & 12 & 7 & \multirow{4}{*}{$p<0.0001$} \\
\hline 3-3.9 & 238 & 122 & 116 & \\
\hline $4-4.9$ & 222 & 112 & 110 & \\
\hline$\geq 5$ & 21 & 7 & 14 & \\
\hline \multicolumn{5}{|c|}{ Time spent for brushing (Seconds) } \\
\hline $30-44$ & 183 & 88 & 95 & \multirow{4}{*}{$p<0.001$} \\
\hline $45-59$ & 136 & 71 & 65 & \\
\hline $60-120$ & 181 & 94 & 87 & \\
\hline$\geq 120$ & 0 & 0 & 0 & \\
\hline \multicolumn{5}{|c|}{ Technique of brushing } \\
\hline Correct & 28 & 21 & 7 & \multirow{2}{*}{$p<0.01$} \\
\hline Incorrect & 472 & 233 & 239 & \\
\hline \multicolumn{5}{|c|}{ Parental Supervision } \\
\hline Absent & 453 & 221 & 232 & \multirow{2}{*}{$p<0.001$} \\
\hline Present & 47 & 35 & 12 & \\
\hline \multicolumn{5}{|c|}{ Frequency of parental supervision / week } \\
\hline 0 & 453 & 221 & 232 & \multirow{5}{*}{$p<0.001$} \\
\hline 2 & 3 & 2 & 1 & \\
\hline 3 & 22 & 15 & 7 & \\
\hline 4 & 15 & 13 & 2 & \\
\hline$\geq 5$ & 7 & 7 & 0 & \\
\hline \multicolumn{5}{|c|}{ Frequency of brush change (In months) } \\
\hline 2 & 13 & 5 & 8 & \multirow{5}{*}{$p<0.01$} \\
\hline 3 & 376 & 204 & 172 & \\
\hline 4 & 98 & 40 & 58 & \\
\hline 5 & 5 & 2 & 3 & \\
\hline$\geq 6$ & 8 & 2 & 6 & \\
\hline
\end{tabular}




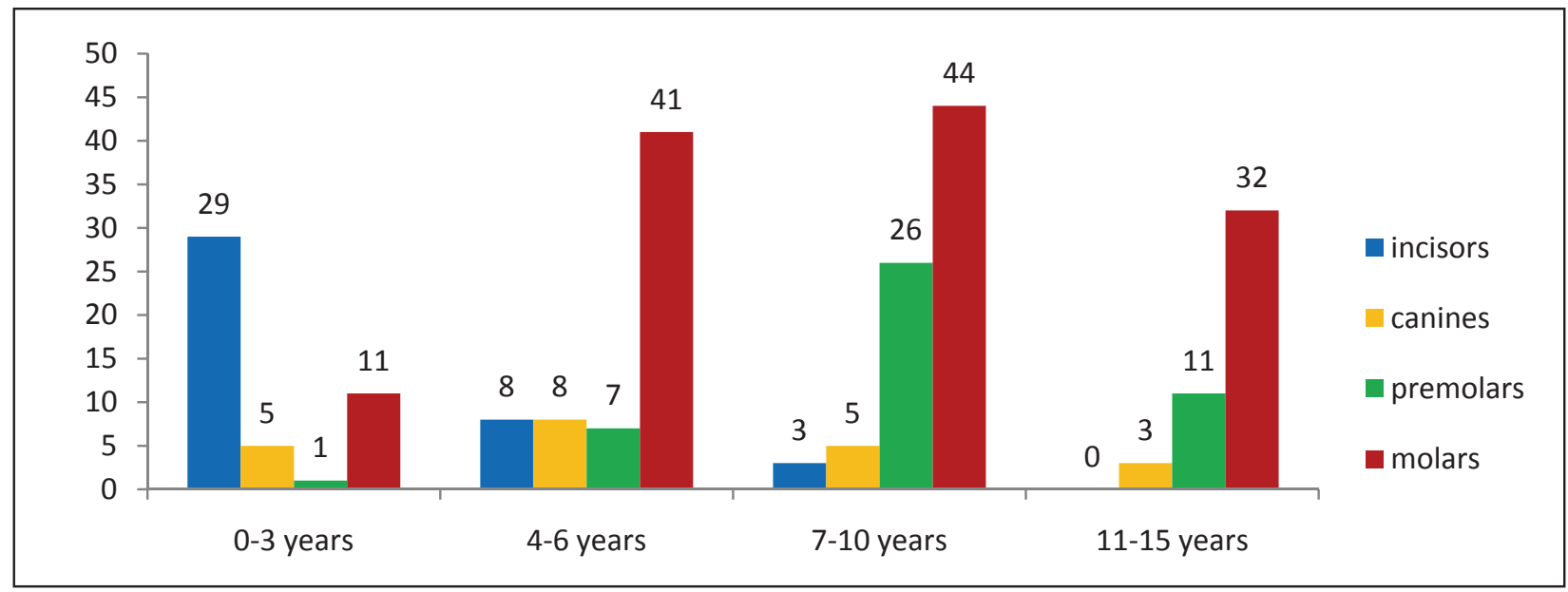

Fig 1: Age specific teeth involvement $(n=234)$

\section{Discussion}

The findings from our study provide useful insights into the oral health risk factors, their prevalence in the community and feasibility of assessment in paediatric office practice. We could not find such studies conducted by paediatrician without help of dentist, so we have tried to compare some of our results with the studies by dental health provider. Most of their studies are targeted to prevalence of caries in specific age group or geographical region or assessment of treatment needs but very few studies are found which focus on large age group and multiple dental health risk factors as in our study.

In our study, past history of dental check up was found in $1.3 \%$ correlating to NOHS (2\%)(2) where as Kalaskar $^{18}$ and Simratvir ${ }^{19}$ et al found it to be $14.3 \%$ and $11.4 \%$. The reasons may be low perception of need or lack of resources.

The overall proportion of dental health problem was $42.8 \%$ in our study, showing upward trend with increasing age. Plaque was most prevalent problem as studied by Long et. $\mathrm{al}^{10}$. Plaque was found more in higher age group which correlates with the results of Sudha et. $\mathrm{al}^{20}$. Plaque accumulation is strongly associated with dental caries ${ }^{4,8,12,16,20}$. Incipient lesions - opaque white spots found in 33 patients which is considered as high risk factor in risk assessment tools for dental caries ${ }^{12,17}$. Overall proportion of caries was $20.5 \%$ which is lesser than other Indian studies. This can be explained by the fact that examination for caries in our study was carried out by a paediatrician and not by dentist, without the use of any dental equipment like mirror or special probe to look for hidden cavities and no radiographs were taken. Still the findings of increasing caries with increase in age $^{18,21,22,23,24,25}$ and the predilection for the type of the teeth $^{24,26.27 .28}$ correlated well with other studies. Recent analysis by Kundu ${ }^{22}$ et. al. on prevalence of caries across WHO index groups over past fifteen years in India showed pooled prevalence to be highest in 15 year age. Greater consumption of cariogenic food and casual neglect of hygiene contributes to more caries in adolescence as it is a continuous and cumulative process. In our study, it may partly be attributed to an ease of examination in the older patients thereby detection of more caries.

Children with special health needs are considered high risk group and require early referral ${ }^{4,8,10,12,17}$. In our study, all the children with cerebral palsy had dental caries.

WHO,AAP, AAPD, NOHS India, systematic review of risk factors by $\mathrm{R}$ Harris and several other studies have shown inverse relation between caries and socioeconomic class, as found in our study ${ }^{1,25,5,6,8,12,16,20,21,29}$. Lack of awareness, improper dietary habits and low literacy level may be contributing factors. Education level of parents ${ }^{1,16,26,30}$ and a positive family history of caries $4,8,10.12 .16 .17$ were significantly correlated with the dental problems in our study as in several other studies.

Malnutrition was found to have significant correlation $(p<0.0001)$ with dental problems as in other studies $^{9,30}$. Systematic review of BMI with caries by Hooley et. $\mathrm{al}^{31}$. shown that there is still a disagreement for the association with BMI, but caries exists with both high and low BMI. We could not study for higher BMI as most of the subjects were with low or normal BMI.

Bottle-feeding was a significant risk factor $(p<0.0001)$ in children up-to three years of age. By three years of age other dietary habits are more important in determining dental caries than bottle feeding ${ }^{16}$. Many studies found similar results for bottle feeding and 
nocturnal bottle feeding ${ }^{12,16,30}$. Systematic review and meta-analysis by Avila et. al. ${ }^{32}$ also concluded that breastfed children are less often affected by dental caries than bottle-fed children. Consumption of sugary beverages and food was found to have significant correlation $(p<0.0001)$ with dental problems. Literature review suggests an established role of cariogenic diet as high risk factor for dental caries at all age groups $5,8,11,12,17$. It was also observed when national and international data were compared ${ }^{10,16,20,24,30}$. Reasons for high sugar consumption in lower socio-economic class could be variety and easy availability of low priced attractive food, exposure to media and advertisements, as well as sugary food distribution for celebration or positive reinforcement.

In present study, age of start of brushing was significantly correlated $(p<0.0001)$ with dental problems as in systematic review by Harris $R$ et. al. ${ }^{16}$ Frequency of brushing more than once and night brushing have been associated with less prevalence of caries in many studies ${ }^{4,10,16,26}$. Such an inference could not be derived from our study as none of the subjects brushed their teeth twice a day. Time spent on brushing was significantly correlated $(p<0.001)$ with dental problems though most of the subjects in our study spent inadequate time for brushing (i.e. less than two minutes). Most of our subjects used toothbrush, similar to studies by Goel $\mathrm{R}$ et. al. ${ }^{23}$ and Venugopal et. $\mathrm{al}^{30}$. This is in contrast to NOHS data which says that only $50 \%$ use a toothbrush in India ${ }^{2}$. It may be because our study population is from urban area while Indian data includes rural population where cultural practices and lack of media influence also play major role. Delayed change of toothbrush was significantly associated with increased frequency of caries. It can be reasoned out that prolonged use of same toothbrush with frayed bristles may lead to improper cleaning and in turn accumulation of plaque.

Parental knowledge of correct technique had statistically significant association with less dental problems, as they have an important role in inculcating

\section{References}

1. WHO Oral Health Fact Sheet, Apr 2012 available at http://www.who.int/mediacentre/factsheets/fs318/en/ (last accessed at 15 Dec 2016)

2. National Oral Health Programme. Wake-up call for action available at http://nohp.org.in/aboutus/ WakeUpCallAction.aspx (last accessed on 5th Dec 2016)

3. Niranjan V. An overview of oral health plan of India: Evaluating current status of oral healthcare and good oral habits at an early age. Parental supervision during brushing was found to be very significant ( $p$ $<0.001$ ) for preventing dental problems, as in study by Mahejabeen et. $\mathrm{al}^{24}$. Family should continue to assist with brushing until child demonstrate adequate coordination, usually by eight years of age $e^{4,5,8}$. Less parental knowledge and assistance in our study may be related to their low literacy level and lower SEC.

\section{Conclusion}

Our study reconfirms various risk factors for dental health problems like lower socio-economic status, lower education levels of parents, family history of dental caries, bottle-feeding, frequent consumption of sugary food and tooth brushing factors e.g. delayed start, inadequate duration, and lack of parental supervision and inadequate parental knowledge of brushing the teeth.

Recommendations: Oral health knowledge of paediatrician can be enhanced by incorporating it in medical curriculum, CME courses or by facilitating comprehensive training programmes. Incorporating oral health into paediatric practice might be a new concept but results of our study suggest that it is feasible even in busy OPD. To save time in busy OPD, paediatrician can shortlist some of the risk factors and train the office/paramedical staff for its assessment and impart health education through brochure/stickon posters/use of media in waiting room, followed by oral cavity examination by himself. Paediatrician has an opportunity to impact oral health status of children through implementation of planned office-based risk assessment and anticipatory guidance and thereby to attain NOHP goal of optimal oral health by 2020 .

Limitations: The limitation of our study was that the population, to which our hospital caters, does not have adequate representation of all socio-economic strata. We have not utilized any special dental equipment (mirror/probe) to examine the teeth which might have led to under diagnosis of dental caries in a few subjects.

advocacy for national oral health policy. J Adv Oral Res 2015;6(3):24-29

4. U.S. Department of Health and Human Services, Health Resources and Services Administration. Oral Health in Primary Care. Rockville, Maryland: U.S. Department of Health and Human Services, 2012

5. American Academy of Pediatric Dentistry. Guideline on infant oral health care. Pediatr Dent 2014;37:146-50

6. Charlotte W. Lewis, David C. Grossman, Peter K. Domoto, Richard A. Deyo - The Role of the Pediatrician in the Oral Health of Children: A National 
Survey. Pediatrics 2000;106(6);e84 DOI: 10.1542/ peds.106.6.e84.

7. AAP policy statement 2013, Preventive Oral Health Intervention for Pediatricians. Pediatrics 2008;122(6):1387-94.

8. Tinanoff N. The oral cavity, Nelson a textbook of paediatrics, ch $304,1254-56,18^{\text {th }}$ edition.

9. Chandna P, Adlakha VK. Oral health in children: guidelines for pediatricians. Indian Pediatr 2010;47:323-327

10. Long et al.: Pediatricians' assessments of caries risk and need for a dental evaluation in preschool aged children. BMC Pediatrics 2012;12:49.

11. American Academy of Pediatric Dentistry. Guidelineon Periodicity of Examination, Preventive Dental Services, Anticipatory Guidance/Counseling, and Oral Treatment for Infants, Children, and Adolescents, Pediatr Dent 2013;123-30

12. American Academy of Pediatric Dentistry. Guideline on Caries-risk Assessment and Management for Infants, Children, and Adolescents, Pediatr Dent 2014;37:1329

13. Murthy G A, Mohandas U. The knowledge, attitude and practice in prevention of dental caries amongst pediatricians in Bangalore: A cross-sectional study. $J$ Indian Soc Pedod Prev Dent 2010;28:100-3

14. Bhat Sham S. et al: Pediatrician views about oral health care, Indian J Pediatr 2006;73;6:535-36

15. Oral Health Surveys, Basic Methods. 5th ed. Geneva: WHO; 2013. World Health Organisation

16. Harris RV, Nicoll AD, Adair PM, Pine CM. Risk factors for dental caries in young children: a systematic review of the literature. Community Dental Health 2004;21(Suppl.)71-85.

17. American Academy of paediatrics, oral health assessment tool 2011 available at http://www2.aap.org/ commpeds/dochs/oralhealth/RiskAssessmentTool. html (last accessed at 6th October 2016)

18. Kalaskar RR, Kalaskar AR, Chandorikar H, Hazarey $\mathrm{S}$. Prevalence of dental caries and treatment needs in school going children of Vidarbha region, central India. Univ Res J Dent 2015;5:68-72.

19. Simratvir M, Moghe GA, Thomas AM, Singh N, Chopra $\mathrm{S}$ : Evaluation of caries experience in 3-6-year-old children, and dental attitudes amongst the caregivers in the Ludhiana city. J Indian Pedod Prev Dent 2009;27:164-69.

20. Sudha P, Bhasin S, Anegundi RT. Prevalence of dental caries among 513-year-old children of Mangalore city. J Indian Soc Pedod Prev Dent 2005;23:749.
21. Moses, J., Rangeeth, B. N., \& Gurunathan, D. (2011). Prevalence of dental caries, socio-economic status and treatment needs among 5 to 15 year old school going children of Chidambaram. Dentistry 2011;5(1):146-51.

22. Kundu H, Patthi B, Singla A, Jankiram C, Jain S, Singh K. Dental caries scenario among 5, 12 and 15-year-old children in India- A retrospective analysis. J Clin Diagn Res 2015;9(7):ZE01-ZE05.

23. Goel R, Vedi A, Veeresha KL, Sogi GM, Gambhir RS Oral hygiene practices and dental caries prevalence among 12 \& 15 years school children in Ambala, Haryana -A cross-sectional study. J Clin Exp Dent 2015;7(3):e374-79

24. Goyal A, Gauba K, Chawla HS, Kaur M, Kapur A. Epidemiology of dental caries in Chandigarh school children and trends over last 25 years. Indian Soc Pedod Dent 2007;25(3);115-8

25. Dash JK, Sahoo PK, Bhuyan SK, Sahoo SK. Prevalence of dental caries and treatment needs among children of Cuttack (Orissa). J Indian Soc Pedod Prev Dent 2002;20:139-43

26. Kumar A, Dutta S, Namdev R, Mehta R, Hooda A, Goel M. Prevalence and Relationship between Dental Caries, Diet and Nutrition, Socioeconomic Status and Oral Hygiene Habits in Children Using Laser Fluorescence Device (Diagnodent). Journal of Oral Health \& Community Dentistry, 2014;8(1):

27. Prabhu P, Rajajee KT, Sudheer KA, Jesudass G. Assessment of caries prevalence among children below 5 years old. $J$ Int Soc Prev Community Dent 2014:4:40-3.

28. Mahejabeen R, Sudha P, Kulkarni SS, Anegundi R. Dental caries prevalence among preschool children of Hubli: Dharwad city. J Indian Soc Pedod Prev Dent 2006;24:19-22

29. Sogi $G$ and Baskar D.J: Dental caries and oral hygiene status of 13-14 year old school children of Davangere. J Indian Soc Pedo Prev Dent 2001;19(3):113-117.

30. Venugopal T, Kulkarni VS, Nerurker RA, Damle SG, Patnekar PN. Epidemiological study of dental caries. Indian J Pediatr 1998;65:883-9

31. Hooley et al.: Body mass index and dental caries in children and adolescents: a systematic review of literature published 2004 to 2011. Systematic Reviews 2012 1:57.

32. Avila WM, Pordeus IA, Paiva SM, Martins CC. Breast and Bottle Feeding as Risk Factors for Dental Caries: A Systematic Review and Meta- Analysis. PLOS ONE 2015;10(11):e0142922. doi:10.1371/ journal. pone.0142922. 